Assiut Scientific Nursing Journal

http://asnj.journals.ekb.eg

http://www.arabimpactfactor.com

DOI: 10.21608/ASNJ.2021.72930.1162

\title{
Effect of Educational Guidelines on Mothers' Emotional Status regarding Children undergoing Cardiac Catheterization
}

\author{
Hoda Wahid Amer ${ }^{1}$, Doaa Bahig Anwr², Entisar Mohammed Abu Salem ${ }^{3}$, Safaa Mustafa \\ Mohamed $^{4}$ \& Manal Mohamed Ayed ${ }^{5}$ \\ ${ }^{1 .}$ Lecturer of Pediatric Nursing College of Nursing, Misr University for Science \& Technology, Egypt \\ 2. Lecturer of Pediatric Nursing Department, Faculty of Nursing, Aswan University, Egypt \\ ${ }^{3 .}$ Lecturer of Psychiatric Mental Health Nursing Department, Faculty of Nursing, Beni-Suef University, Egypt \\ 4. Lecturer of Psychiatric Nursing Department, Faculty of Nursing, Sohag University, Egypt \\ 5. Assistant Professor of Pediatric Nursing Department, Faculty of Nursing, Sohag University, Egypt
}

\begin{abstract}
:
Pediatric cardiac catheterization is applied for diagnostic and therapeutic procedures to children with congenital and acquired heart diseases. Aim: To evaluate the effect of educational guidelines on mothers' emotional status regarding children undergoing cardiac catheterization. Design: A quasi-experimental research design with a pre-and post-test was used. Setting: The study was conducted at the intensive care, catheterization, and cardiac care unit at Sohag University Hospital. Subjects: A convenient sample of 70 mothers of children who diagnosed with cardiac defects undergoing cardiac catheterization was involved in the current study. Tools for data collection Two tools were used in the current study first tool was mothers' interviewing questionnaire (pre/post), which included demographic characteristics; and mothers' knowledge regarding cardiac catheterization and second tool was Depression, Anxiety, and Stress Scale (DASS). Results: After implementation of the guidelines, significant relationship and improvements were detected between mothers' knowledge about their children's cardiac catheterization than before and mothers' emotional status (stress, depression, and anxiety levels) were severe before implementation of the guidelines while these levels become low after guidelines implementation. Conclusion: The guidelines for mothers of children undergoing cardiac catheterization had a positive effect on improving their knowledge and minimizing mothers' emotional disturbances like depression, anxiety, and stress regarding their children's cardiac catheterization after implementation of the guidelines than before. Recommendations: The guidelines for mothers of children undergoing cardiac catheterization should be conducted to raise their awareness. Psychological support and intervention activities should be carried out to help mothers to become emotionally stable.
\end{abstract}

\section{Keywords: Cardiac catheterization, Educational guidelines, Emotional status \& Mothers.}

\section{Introduction:}

Heart diseases in pediatric patients are lifethreatening events; that affect the child's health and their families. Approximately 1 in 120 babies are born with heart disease. It may occur as a result of a problem during the first 8 to 12 weeks of gestation. The specific type of the occurring cardiac malformation varies depending on the environmental trigger and its timing within the vulnerable period. Most alterations in cardiovascular function in children occur as a consequence of defects in the heart that are present at birth as Congenital Heart Disease (CHD) (Hockenberry, et al., 2016).

Cardiac Catheterization (CC) is the suitable procedure for diagnosis and treatment of cardiac diseases. It is the best procedure for assessment and gaining enough data about the anatomy and physiology of the heart cavities, valves, and coronary arteries (Ahmed, 2015). With advanced medical care, more children born with CHD are surviving and because of recent advances in diagnostics, medical treatment, and surgical techniques over the last two decades, the mortality rate of children with CHD has decreased. There are several treatment strategies for the great variety of CHD that are essential to provide the best care to those children. Some of these treatment strategies are open-heart surgery, medical treatment, and cardiac catheterization (Thrush \& Hoffman, 2014).

An obvious advancement has occurred in the field of diagnostic and interventional cardiac catheterization intending to improve the functioning of a heart that is working abnormally. During cardiac catheterization, a catheter is inserted into a vein in a child from a jugular access site. Cardiac catheterization has played an important role in diagnostic precision and the standard of care before initiation of therapy and for ongoing evaluation of therapeutic strategies. Diagnostic CC in children is still having a gold standard role because acquired data must be accurate for the presurgical assessment of children with CHD to better guide clinical decisions and increasing the safety and efficacy of surgery (Ali, 2016) 
Therapeutic $\mathrm{CC}$ procedures are used as an alternative to open-heart surgery when possible because of the changes that have occurred in the pediatric cardiac catheterization laboratory. Therapeutic CC identifies procedures where cardiac catheters are used for modification, palliation, or treatment of congenital or acquired heart defects. These therapeutic procedures include closure of Atrial Septal Defects "(ASD), Ventricular Septal Defects VSD”, Closure of Patent Ductus Arteriosis PDA, Expansion of "Pulmonary Stenosis", Stent Placement, and the Creation of Holes such as Septostomy, Valvoplasty (Kanter, et al., 2015).

Mothers are more likely to be anxious about the health and safety of their children. Stress and anxiety regarding school reopening reflect a higher level of worry for mothers because of the increased risks. Parental anxiety assessment is very important because it is contributed to child stress. Knowledge given to parents, as with children, should be individualized depend on their cultural and intellectual abilities, their previous experience of hospitalization knowledge, and their emotional needs. It is also, very important to provide accurate information and to correct misconceptions that are often related to their experiences of other family members and friends who have undergone heart catheterization. Parents need information about what to expect during the child's hospital stay, their roles, and how to support their child to minimize anxiety, promote patient comfort, and facilitate the procedure performance that help occurred as safely as possible (Nakamura, et al., 2021).

Stressors may be related to (1) bodily injury of children , pain, mutilation, or their death; (2) separation from their parents and dealing with other strangers persons (3) fear of mothers from unknown; (4) uncertainty feelings and knowledge about limits and acceptable behavior; and (5) loss of control, autonomy, and competence (6) lack of suitable information; (7) the environment of intensive care unit (ICU); and (8) postoperative changes regarding the child's behavior and appearance (Greenberg, et al., 2019 \& Kaugars et al., 2018).

The mothers of children who have experienced major illness require significant medical intervention and time in an intensive care unit (ICU) often at a risk for developing anxiety. Anxiety can increase to $39 \%$ among mothers of children who spend time in the neonatal ICU after birth (Mirhosseini et al., 2015)

Mothers' coping strategies is dependent on several problem-solving skills. Successful coping is associated with the child and their parent's perception about the event (Cohen, et al., 2017).

Mothers have an important role in providing effective emotional support and they should be prepared and encouraged to participate in their normal parenting routines (including nutrition, bathing, playing, reading stories, cuddling) while the child is hospitalized as well as rooming-in should be provided for younger children to decrease the stress of separation. Mothers can learn to support their children by teaching them about procedures and relaxation techniques (Tesson, et al., 2019). Pediatric nurses also, help in procedure preparation for hospitalized children and provide care in outpatient clinics and office settings and using strategies to manage stressors (Heikkinen, (2020).

\section{Significance of the study:}

Congenital heart disease is considered a major problem causes morbidity and mortality in pediatric that accounted for 8 to 12/1,000 live births (Centers for Disease Control \& prevention, 2015). There was an increase in the frequency of children having cardiac defects undergoing cardiac catheterization. Mothers of children diagnosed with congenital heart diseases are at high risk for emotional disturbances related to their children morbidity from these defects. Hopefully, the results of the present study will help in improving the mothers' knowledge and reducing emotional disturbances regarding children's cardiac catheterization. In Egypt despite the routine provided at the moment of discharge care after cardiac catheterization to help mothers in caring for their children, the mothers still needs educational program care to help them after cardiac catheterization and support, guidance, and prepare mothers to care with their children to maintain successfully outcomes which provide the mothers with knowledge to improve quality of care of their children after discharge from the hospital after cardiac catheterization. Sufficient support and knowledge for mothers about cardiac catheterization can also, reduce depression, anxiety, and stress levels and indirectly achieve better outcomes for mothers and their children. Hence, the current study was conducted to evaluate the effect of educational guidelines on mothers' emotional status regarding children undergoing cardiac catheterization.

\section{Aim of the study}

The current study aims to evaluate the effect of educational guidelines on mothers' emotional status regarding children undergoing cardiac catheterization. Research hypothesis:

H1: Mothers of children undergoing cardiac catheterization will have higher mean scores of knowledge after implementation of the educational guidelines than before.

$\mathrm{H} 2$ : Mothers of children undergoing cardiac catheterization will have a low level of emotional 
disturbance as stress, anxiety, and depression after implementation of the educational guidelines.

\section{Subjects and Methods: \\ Research design:}

A quasi-experimental research design (pre and posttest) was utilized in this study.

\section{Setting:}

The study was conducted at the intensive care, pediatric catheterization, and cardiac care units affiliated with Sohag University Hospital, Egypt, the settings were selected because the high prevalence of mothers are attending in these units, and also it serves the biggest region of the population from both rural and urban areas. It included five rooms, their capacities are 40 patients, two rooms from the five are contained ten beds, five beds in each one and the other three rooms contained thirty beds.

\section{Subjects:}

A convenient sample of 70 mothers of children diagnosed with cardiac defects undergoing cardiac catheterization was involved in the current study within six months.

\section{Data collection Tools:}

Two tools were used to collect the data of the study as the following:

Tool (I): Mothers' interviewing questionnaire: it was developed by the researchers (pre/post format). It was written and adapted into the Arabic language to evaluate the effect of educational guidelines on mothers' emotional status regarding children undergoing cardiac catheterization. It included two parts:

Part I: Included demographic characteristics of the studied mothers as age, level of education, working status, and residence.

Part II: Included thirty (30) questions developed by the researchers to assess mothers' knowledge regarding their children's cardiac catheterization such as the meaning of cardiac catheterization, indications for cardiac catheterization, complications of cardiac catheterization, post-care of catheterization, and questions related to cardiac catheterization such as wound dressing, medication, physical activity, exercise, and follow up.

\section{Scoring system:}

The total mothers' knowledge percentages were calculated for known and unknown answers. Each complete correct answer was given ( 2 marks) and an incomplete correct answer was given (1) and (zero) for wrong or unknown answers. The total score of sixty reflected $100 \%$ and then categorized as follows: (good, fair, and poor) the total score of good and fair levels was considered as satisfactory while the level of poor was considered as unsatisfactory. Good level reflected score from $75 \%$ to $100 \%$, fair level reflected score from $50 \%$ to $75 \%$, and poor level reflected score below $50 \%$.

\section{Tool II: Depression, Anxiety and Stress Scale} (DASS-21):

The researchers used the Depression, Anxiety, and Stress Scale which was adopted from Lovibond \& Lovibond (1995). The scale involved 21 items and consisted of three self-reported scales to measure the symptoms of the emotional state of depression, anxiety, and stress. Each of the three DASS-21 subscales contains seven items. Depression scale was used to assess hopelessness, dysphoria, and devaluation of life, lack of interest/involvement, selfdeprecation, anhedonia, and inertia. The anxiety scale was used to measure autonomic arousal, skeletal muscle symptoms, subjective experience of anxious affect, and situational anxiety. The stress scale was used to assess sensitivity of levels of chronic nonspecific arousal. It assesses nervous arousal, difficulty relaxing and being easily upset/agitated, irritable/over-reactive, and impatient. The rating scale responses ranged from (3) applied to express me very much or most of the time; (2) applied to express to a considerable degree or a good part of the time; (1) applied to express some of the time or to some degree; and (zero) did not apply to at all.

\section{Scoring system for (DASS):}

The scale responses were categorized with the cutoff point adopted by Antony et al. (1998) to categorize stress, anxiety, and depression. Thus, the level of symptoms (extremely severe, severe, moderate, mild, and no symptoms) was as follows:

\begin{tabular}{|l|c|c|c|}
\hline $\begin{array}{l}\text { Levels of DASS } \\
\text { symptoms }\end{array}$ & Depression & Anxiety & Stress \\
\hline $\begin{array}{l}\text { Normal } \\
\text { (no symptoms) }\end{array}$ & $0-9$ & $0-7$ & $0-14$ \\
\hline Mild & $10-13$ & $8-9$ & $15-18$ \\
\hline Moderate & $14-20$ & $10-14$ & $19-25$ \\
\hline Severe & $21-27$ & $15-19$ & $26-33$ \\
\hline Extremely Severe & $28+$ & $20+$ & $34+$ \\
\hline
\end{tabular}

Field of work:

Preparatory and assessment Phase: the researchers reviewed the current and past available literature, the available textbooks, articles, magazines, and internet search to develop the tools for data collection and prepare the educational guidelines.

Before starting the study, Administrative permission was obtained from the directors of Sohag University Hospital, and permission from the head of the catheterization, intensive care, and cardiac care units. The researchers introduced their selves to the mothers. Written informed consent was obtained from mothers to get their acceptance. Clear and simple explanations about the aim and nature of the study 
were discussed by the researchers with mothers. Pretest for assessing mothers' level of knowledge (tool 1 part 2) after that the researchers were assessed mothers' depression, anxiety, and stress levels using DASS (tool 2).

\section{Implementation phase:}

The study included 70 mothers of children diagnosed with cardiac defects undergoing cardiac catheterization. The researchers attended the previously mentioned settings of the study two days / a week from 9 am to $11 \mathrm{am}$. The period of data collection was 6 months from the beginning of July 2019 until the end of December 2019. Data were collected from the studied mothers through interviewing questionnaires and the DASS was used twice. Each participant took, approximately, 25-40 minutes to complete the interview questionnaire and the DASS questionnaire.

The questionnaire and the DASS were used twice. For the first time, these were used as a pretest for the assessment of mothers' knowledge about cardiac catheterization and their level of depression, anxiety, and stress. Then, these tools were used another time as after one week to reevaluate the effect of educational guidelines on mothers' knowledge and their level of stress, anxiety, and depression regarding cardiac catheterization. Each mother was informed about the purpose of the study, the components of the tools, and how to answer the questionnaire and the scale.

The guidelines were used as a supportive material and given to mothers in the form of simple Arabic illustrated educational guidelines about cardiac catheterization care for the child. It was prepared by the researchers and explained to the mothers. Educational guidelines illustrated in the form of in Arabic booklet, educational videos and pictures also utilized and distributed to each mother.

The instructional guidelines included knowledge about oral health as follow:

- Simple information about congenital heart disease

- Cardiac catheterization (indications, preparation and its complications)

- Care of the puncture site,

- Medications (antibiotics and pain management)

- Hygienic care

- Fluid intake

- Activities

- Follow up

\section{Validity and reliability:}

Face validity for the tools and the educational guidelines were carried out by five experts in the pediatric nursing and psychiatric health nursing field for testing its clarity, comprehensiveness, and appropriateness to test the content validity before using it in the study. No modifications were done according to the panel judgment.

The Cronbach's $\alpha$ test was used to assess the reliability of the questions relating to knowledge, which was 0.89.

\section{Pilot study}

It was conducted for $10 \%$ of the studied mothers ( 7 mothers). The clarity and testing of the feasibility of the research process needed for modifications were carried out to develop the final form of the tools. Mothers involved in the pilot study were included in the study.

Administrative and Ethical Considerations:

Administrative permission was obtained through an issued letter from the Dean of Faculty of Nursing, Sohag University to the head of the catheterization, intensive care, and cardiac care units. The aim of the research was explained and the expected outcomes from the implementation of the study were included in this letter to obtain permission to collect the research data. The objective of the research was explained to the mothers. The researcher informed the participants that, the study was voluntary; they were allowed to refuse to participate in the study. Mothers had the right to withdraw from the study at any time, without giving any reason. Mothers were assured that their information would be confidential and used for research purposes only.

\section{Statistical analysis:}

Data entry was performed using SPSS for Windows, version 20. Data were presented using descriptive statistics in the form of frequencies and percentages for qualitative variables and mean and SDs for quantitative variables. Differences between two means tests (t-test) were used. Statistical significance was considered when $\mathrm{P}$-value $<0.05$. 


\section{Results:}

Table (1): Percentage distribution of studied mothers of children undergoing cardiac catheterization according to their demographic characteristics $(n=70)$

\begin{tabular}{|c|c|c|}
\hline \multirow{2}{*}{ Demographic characteristics } & \multicolumn{2}{|c|}{ Studied mothers (70) } \\
\hline & No. & $\%$ \\
\hline \multicolumn{3}{|l|}{ Mothers age in years } \\
\hline $18<21$ & 14 & 20 \\
\hline $21<26$ & 28 & 40 \\
\hline $26<30$ & 17 & 25 \\
\hline $30<35$ & 6 & 8 \\
\hline $35<40$ & 5 & 7 \\
\hline Mean \pm Stander Deviation & \multicolumn{2}{|c|}{$22.8 \pm 7.67$} \\
\hline \multicolumn{3}{|l|}{ Mothers' education } \\
\hline Illiterate & 7 & 10 \\
\hline Read and write & 14 & 20 \\
\hline Primary education & 16 & 23 \\
\hline Secondary education & 18 & 25 \\
\hline University education & 15 & 22 \\
\hline \multicolumn{3}{|l|}{ Working Condition } \\
\hline Working & 20 & 29 \\
\hline Housewives & 50 & 71 \\
\hline \multicolumn{3}{|l|}{ Residence } \\
\hline Rural & 58 & 83 \\
\hline Urban & 12 & 17 \\
\hline
\end{tabular}

Table (2): Distribution of the studied mothers in the pre and post implementation of the educational guidelines related their knowledge about cardiac catheterization

\begin{tabular}{|l|c|c|c|}
\hline \multicolumn{1}{|c|}{ Items of knowledge } & \multicolumn{2}{c|}{ No =(70) } & \multirow{2}{*}{ p-value } \\
\cline { 2 - 3 } & Pre & Post & -val \\
\hline Meaning of cardiac catheterization & $17(24)$ & $66(94)$ & $<0.001^{*}$ \\
\hline Indications for cardiac catheterization & $24(34)$ & $70(100)$ & $<0.001^{*}$ \\
\hline Complications of cardiac catheterization & $26(37)$ & $67(96)$ & $<0.001^{*}$ \\
\hline Post care of catheterization & $34(34)$ & $67(96)$ & $<0.001^{*}$ \\
\hline $\begin{array}{l}\text { Questions related to cardiac catheterization (medications, exercise, and } \\
\text { wound dressing). }\end{array}$ & $12(17)$ & $66(95)$ & $<0.001^{*}$ \\
\hline Follow-up and home care & $17(24)$ & $63(90)$ & $<0.001^{*}$ \\
\hline
\end{tabular}

*Statistically Significant Differences

Table (3): Levels of total knowledge among the studied mothers related cardiac catheterization in the pre and the post-educational guidelines implementation

\begin{tabular}{|c|c|c|c|c|c|c|}
\hline \multirow{3}{*}{ Total knowledge } & \multicolumn{4}{|c|}{ No $=(70)$} & \multirow{3}{*}{$\mathrm{X}^{2}$} & \multirow{3}{*}{ p-value } \\
\hline & \multicolumn{2}{|c|}{ Pre } & \multicolumn{2}{|c|}{ Post } & & \\
\hline & No & $\%$ & No & $\%$ & & \\
\hline Poor $<\mathbf{5 0}$ & 39 & 54 & 2 & 3 & \multirow{3}{*}{8.074} & \multirow{3}{*}{$<0.001 *$} \\
\hline Average $(50<75)$ & 25 & 37 & 18 & 25 & & \\
\hline Good (75-100) & 6 & 9 & 50 & 72 & & \\
\hline
\end{tabular}

*Statistically significant level at $P<.001$

Table (4): Total means scores of the studied mothers' emotional status (depression, anxiety, and stress) in the pre and the post the educational guidelines' implementation related cardiac catheterization

\begin{tabular}{|l|c|c|c|}
\hline \multirow{2}{*}{ DASS } & \multicolumn{2}{|c|}{ No $=\mathbf{( 7 0 )}$} & \multirow{2}{*}{ p-value } \\
\cline { 2 - 3 } & Pre & Post & \\
\hline Depression & $25.60 \pm 3.52$ & $12.60 \pm 1.40$ & $<0.001^{*}$ \\
\hline Anxiety & $18.40 \pm 1.13$ & $11.84 \pm 1.15$ & $<0.001^{*}$ \\
\hline Stress & $31.60 \pm 3.72$ & $24.30 \pm 3.68$ & $<0.001^{*}$ \\
\hline
\end{tabular}

*Statistically Significant Differences 


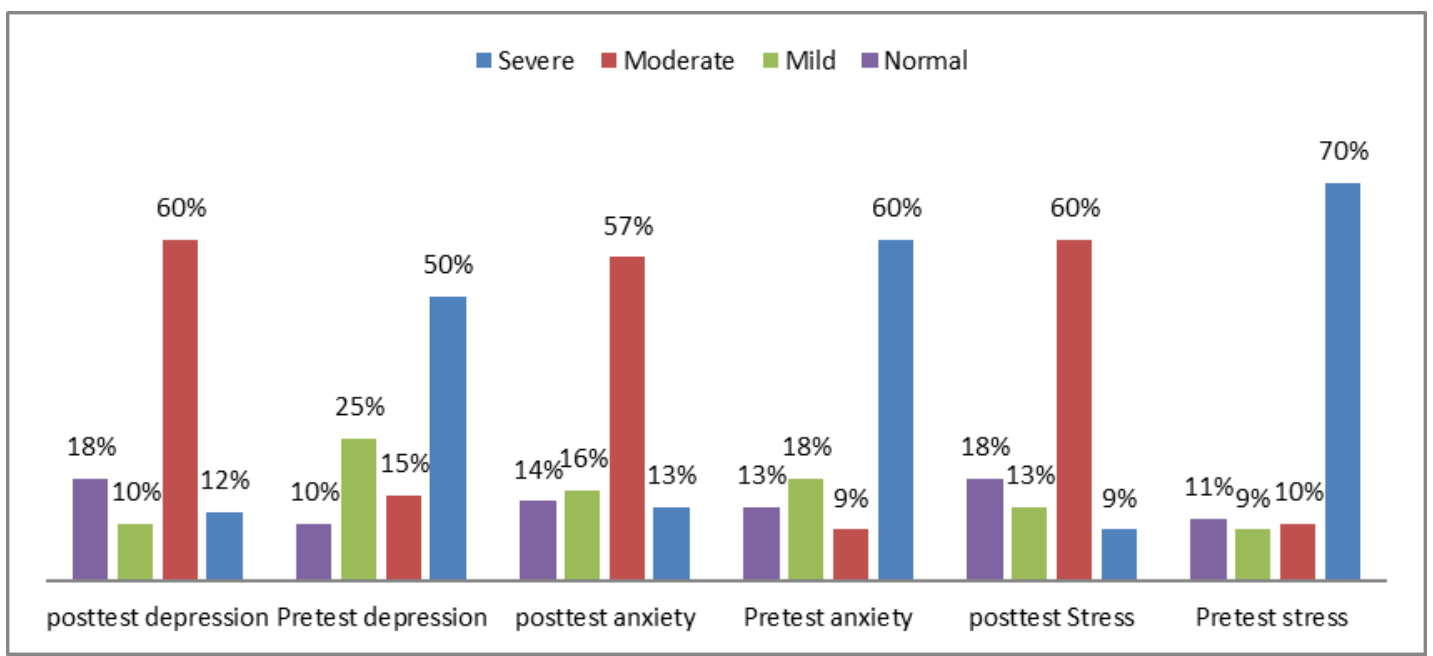

Figure (1): Percentage distribution of the studied mothers' emotional status (depression, anxiety, and stress level) in the pre and the post educational guidelines' implementation related cardiac catheterization(n=70)

Table (5) Correlation between socio-demographic characteristics of the studied mothers and their total level of knowledge about cardiac catheterization in the pre and the post education guidelines' implementation $(\mathbf{N}=\mathbf{7 0})$

\begin{tabular}{|c|c|c|c|}
\hline \multirow{2}{*}{ Demographic characteristics } & \multicolumn{3}{|c|}{ Spearman's rank correlation coefficient (r) } \\
\cline { 2 - 4 } & \multicolumn{3}{|c|}{ Knowledge } \\
\cline { 2 - 4 } & Pre-intervention & Post-intervention & Overall \\
\hline Age & -.137 & -.203 & -.091 \\
\hline Education & .136 & $.305^{* *}$ & $.178^{*}$ \\
\hline Working & -.102 & -.137 & -.072 \\
\hline Residence & .063 & .087 & .027 \\
\hline
\end{tabular}

* Statistically Significant Differences

Table (6) Association between socio-demographic characteristics of the studied mothers and their mean scores of emotional states (depression, anxiety, and stress) in the pre and the post educational guideline's implementation $(\mathbf{N}=70)$

\begin{tabular}{|c|c|c|c|c|c|c|c|}
\hline \multirow{3}{*}{$\begin{array}{c}\text { Mothers' } \\
\text { characteristics }\end{array}$} & \multicolumn{6}{|c|}{ DASS } & \multirow{3}{*}{ p-value } \\
\hline & \multicolumn{2}{|c|}{ Depression } & \multicolumn{2}{|c|}{ Anxiety } & \multicolumn{2}{|c|}{ Stress } & \\
\hline & Pre & Post & Pre & Post & Pre & Post & \\
\hline $\begin{array}{c}\text { 1-Age(years): } \\
-18<26 \\
-26-34 \\
-34 \geq 40\end{array}$ & $\begin{array}{l}22.55 \pm 3.60 \\
23.70 \pm 3.60 \\
24.70 \pm 3.60\end{array}$ & $\begin{array}{l}11.45 \pm 2.60 \\
13.60 \pm 1.40 \\
12.60 \pm 1.40\end{array}$ & $\begin{array}{l}15.55 \pm 3.60 \\
16.60 \pm 3.60 \\
17.80 \pm 1.12\end{array}$ & $\begin{array}{l}10.12 \pm 1.60 \\
12.83 \pm 1.13 \\
11.83 \pm 1.13\end{array}$ & $\begin{array}{l}30.40 \pm 3.60 \\
31.50 \pm 2.60 \\
32.70 \pm 3.60\end{array}$ & $\begin{array}{l}23.25 \pm 3.60 \\
22.30 \pm 3.60 \\
24.40 \pm 3.70\end{array}$ & $<0.001 *$ \\
\hline $\begin{array}{l}\text { 2-Educational level: } \\
\text { - Illiterate } \\
\text { - Read and write } \\
\text { - Primary education } \\
\text { - Secondary } \\
\text { education } \\
\text { - University } \\
\text { education } \\
\end{array}$ & $\begin{array}{l}23.70 \pm 3.60 \\
22.55 \pm 3.60 \\
21.60 \pm 2.60 \\
24.70 \pm 3.60 \\
20.50 \pm 3.20\end{array}$ & $\begin{array}{l}13.60 \pm 1.40 \\
11.45 \pm 2.60 \\
12.50 \pm 2.60 \\
12.60 \pm 1.40 \\
12.60 \pm 1.40\end{array}$ & $\begin{array}{l}16.80 \pm 1.12 \\
15.55 \pm 3.60 \\
16.60 \pm 3.60 \\
17.80 \pm 1.12 \\
15.30 \pm 1.10\end{array}$ & $\begin{array}{l}12.83 \pm 1.13 \\
10.12 \pm 1.60 \\
10.12 \pm 1.60 \\
11.83 \pm 1.13 \\
11.43 \pm 1.12\end{array}$ & $\begin{array}{l}33.70 \pm 3.60 \\
30.45 \pm 3.60 \\
31.50 \pm 2.60 \\
32.70 \pm 3.60 \\
30.50 \pm 3.50\end{array}$ & $\begin{array}{l}24.40 \pm 3.70 \\
21.25 \pm 3.60 \\
22.30 \pm 3.60 \\
23.40 \pm 3.70 \\
23.30 \pm 3.60\end{array}$ & $0.004 *$ \\
\hline $\begin{array}{l}\text { 3- Working status: } \\
\text { - Housewives } \\
\text { - Working }\end{array}$ & $\begin{array}{l}21.60 \pm 2.60 \\
24.70 \pm 3.60 \\
\end{array}$ & $\begin{array}{l}12.50 \pm 2.60 \\
12.60 \pm 1.40\end{array}$ & $\begin{array}{l}16.60 \pm 3.60 \\
17.80 \pm 1.12 \\
\end{array}$ & $\begin{array}{l}10.12 \pm 1.60 \\
11.83 \pm 1.13\end{array}$ & $\begin{array}{l}31.50 \pm 2.60 \\
32.70 \pm 3.60 \\
\end{array}$ & $\begin{array}{l}22.30 \pm 3.60 \\
23.40 \pm 3.70 \\
\end{array}$ & $0.003 *$ \\
\hline $\begin{array}{l}\text { 4- Residence } \\
\text { - Urban } \\
\text { - Rural }\end{array}$ & $\begin{array}{l}22.60 \pm 3.60 \\
24.70 \pm 3.60\end{array}$ & $\begin{array}{l}11.50 \pm 2.60 \\
12.60 \pm 1.40\end{array}$ & $\begin{array}{l}15.60 \pm 3.60 \\
17.80 \pm 1.12\end{array}$ & $\begin{array}{l}10.12 \pm 2.60 \\
11.83 \pm 1.13\end{array}$ & $\begin{array}{l}30.50 \pm 3.60 \\
32.70 \pm 3.60\end{array}$ & $\begin{array}{l}21.30 \pm 3.60 \\
23.40 \pm 3.70\end{array}$ & $<0.001 *$ \\
\hline
\end{tabular}

*Statistically Significance differences 
Table (1): Showed that $40 \%$ of the studied mothers, their age was ranged between $21<26$ years and their mean age $(22.8 \pm 7.67)$. One quarter $(25 \%)$ of them had secondary education, $71 \%$ were housewives, majority of them $(83 \%)$ were living in rural areas.

Table (2): Pointed that there were significant increasing of mothers percentages in the post implementation of the educational guidelines related their knowledge about cardiac catheterization than in the pretest improvement in the studied mothers' knowledge and a high statistically significant differences were found in the post implementing educational guidelines as compared to the preimplementing guidelines related all items in the table (P-value $<0.001)$. Illustrated correct answers of the studied mothers in the pre and post implementation of the educational guidelines related their knowledge about cardiac catheterization

Table (3): Illustrated that a highly statistically significant difference was found between levels of total knowledge among the studied mothers related cardiac catheterization in the pre and the post educational guidelines implementation $(\mathrm{p}<0.001)$. More than half of mothers $(54 \%)$ had a poor level of knowledge about cardiac catheterization in the pretest but after educational guidelines' implementation, $(72 \%)$ of them had a good level of knowledge.

table (4): Concerning mothers' total scores of depression, anxiety, and stress, it was observed from the that, the total mothers' depression, anxiety, and stress mean scores were high before the educational guidelines' implementation and a highly statistically significant decreasing was observed in mothers' total mean scores of depression, anxiety and stress after the educational guidelines' implementation $(\mathrm{P}<0.001)$ which mean positive effects of the educational guidelines provided by the researchers to the mothers. Figure (1): Illustrated that, $(70 \%)$ of the studied mothers before the educational guidelines' implementation had a severe level of stress, $(60 \%)$ of mothers had severe anxiety and $(50 \%)$ of them had severe depression while these percentages decreased to be moderate in more than half of them post educational guidelines' implementation.

Table (5): Illustrated that a statistically significant positive relationship was detected between the educational level of the studied mothers and overall knowledge, throughout the educational guidelines at $\mathrm{p}<0.01$. Where, there was an improvement of the knowledge among educated mothers than noneducated.

Table (6): Clarified that, a highly statistically significant differences were observed between the socio-demographic characteristics as age, education, working status and the residence, and the total scores of depression, anxiety, and stress among the studied mothers in the pre and the post educational guidelines' implementation related to cardiac catheterization with decreasing in the totals scores of depression, anxiety and stress in the post educational guidelines' implementation than before. Also, mothers aged $34 \geq$ to 40 , had a secondary level of education, were working, and were from rural areas had more depression, anxiety, and stress before the educational guidelines' implementation but these scores decreased after the educational guidelines' implementation.

\section{Discussion:}

Cardiac catheterization represented a vital role in diagnostic precision; it is considered the standard of care before initiation of therapy, and therapeutic strategies. The study was aimed to evaluate the effect of educational guidelines on mothers' emotional status regarding children undergoing cardiac catheterization. The results of the present study revealed that an improvement in the studied mothers' knowledge was found in the post-implementation of educational guidelines as compared to pre-implementation of educational guidelines with a high statistically significant difference $(\mathrm{P}$-value $<0.001)$. This reflects the effectiveness of educational guidelines on mothers' knowledge.

The present study findings indicated that a highly significant differences were observed in the total knowledge of studied mothers between the pre and the post- education guidelines implementation $(\mathrm{p}<0.001)$. These findings are supported by (Elgazzar, \& Keshk, 2018) who studied "Effectiveness of nursing care protocol on knowledge and performance among staff nurses regarding the management of patients undergoing coronary angioplasty" and found that the score of knowledge after implementation of the protocol was increased than before in total knowledge regarding the management of patients with coronary angioplasty

The results of this study indicated that more than half of the participated mothers had a poor level of knowledge about cardiac catheterization in the pretest but after educational guidelines' implementation, less than three-quarters of mothers had a good level of knowledge. This has confirmed the need of the mothers to educational guidelines implementation to improve their knowledge about cardiac catheterization and reflected that the guidelines had affected positively on the knowledge of mothers. These findings are supported by (Kobayashi et al., (2015) who found that parents ' knowledge improved after educational guidelines implementation regarding cardiac catheterization.

The findings of the present study revealed that highly statistically significant improvements was noticed in mothers' total scores of depression, anxiety, and stress 
scores after the educational guidelines' implementation regarding cardiac catheterization $(\mathrm{P}<0.001)$. This may indicate the importance of implementing the guidelines that can lead to depression, anxiety and stress reduction. This result is in the same line with Hearps et al., (2014) who conducted study about Psychosocial risk in families of infants undergoing surgery for a serious congenital heart disease and found that mothers of children undergoing cardiac catheterization had high anxiety and stress levels that improved after education.

The results of this study indicated that the studied mothers before the educational guidelines' implementation had a severe level of stress, severe anxiety, and severe depression while these percentages decreased to be moderate in more than half of them post educational guidelines' implementation. These results explained that knowledge deficit causes increasing emotional disturbances. These findings are in the same line with Lakatos, et al, (2019) who conducted a study about "Prevalence and correlations of posttraumatic stress and postpartum depression among parents of infants in the Neonatal Intensive Care Unit (NICU)" and found that majority of parents reported that they were experiencing psychological distress regarding their infant in the neonatal intensive care. Similary, Kobayashi, et al, (2018) studied "Parental anxiety among children undergoing cardiac catheterization" and reported that mother anxiety level was very high regarding their children undergoing cardiac catheterization.

The findings of this study revealed that a significant relationship was detected between the studied mothers' emotional status (depression, anxiety, and stress levels) and their total knowledge pre and postthe instructional guidelines' implementation $(\mathrm{P}<$ 0.05). This may confirm that providing appropriate guidelines for the parents about health services could increase mothers' abilities to cope effectively with ongoing stressors they face. This result is supported by Siu et al., (2016) who found that relationship was found between the studied mothers' emotional status and their total knowledge.

The study findings showed that there was a statistically significant relationship between the educational level of the studied mothers and overall knowledge, throughout the educational guidelines at $\mathrm{p}<0.01$. This may be explained by that educated mothers had more knowledge than low-educated mothers or illiterate that may interfere with their understanding.

The study findings highlighted that there was a statistically significant correlation between the sociodemographic characteristics and the total depression, anxiety, and stress mean scores among the studied mothers in the pre and the post-educational guidelines' implementation regarding cardiac catheterization. Regarding residence of the studied mothers especially the rural areas are accompanied with high mean scores of their emotional disturbance before implementation of the guideline.

From the researcher point of view, rural areas are different in culture, values, beliefs, and mothers in these areas are more stressed because of deficit medical protective supplies, knowledge deficit, and difficulty in going to the health center or the hospital in urban areas when any suspected complications occurred for their children. Also, a high level of mothers' stress was accompanied by working mothers. This result may be because working mothers leave their children for a long time when they are at work without observation which may increase their stress level about their children undergoing cardiac catheterization.

\section{Conclusion:}

Depend on the findings of the present study and research hypothesis it was concluded that, after implementation of the education guidelines, a significant improvement in the level of knowledge among mothers was found in the current study. A highly statistically significant relation was found between mothers' levels of emotional status with decreasing emotional disturbance symptoms as stress, depression, and anxiety in the post-implementation of the educational guidelines about cardiac catheterization than before. Also there was a positive effect of the educational guidelines on improving the emotional status of the studied mothers and their knowledge about cardiac catheterization.

\section{Recommendations:}

The following recommendations are suggested depend on the results of the present study

- Raising the awareness of mothers' instruction sessions regarding cardiac catheterization guidelines about (home care, late post CC complications, and the child follow-up).

- Psychological support should be carried out to help mothers become less stressed and anxious.

- Simple Arabic Booklet and brochures containing sufficient knowledge about cardiac catheterization should be available to mothers in the CC unit, printed and kept in clinics, hospitals and given to all mothers and caregivers of children.

- Further researches are required on a larger sample of mothers to be generalized. 


\section{References:}

- Ahmed, M. (2015): Predictors of post-cardiac catheterization femoral artery hematoma and bleeding, Journal of American Science, 11(3), 1622.

- Ali, S. (2016): Adverse events in pediatric cardiac catheterization: Initial experience of Sohag university hospital. The Egyptian Heart Journal, 68(1), 45-51.

- Antony, M. Bieling, P. Cox, B. Enns, M. \& Swinson, R. (1998): Psychometric properties of the 42-item and 21-item versions of the Depression Anxiety Stress Scales in clinical groups and a community sample. Psychological assessment, 10(2), 176.

- Centers for Disease Control and prevention. (2015): Heart Disease Facts and Statistics.

- Cohen, L., Blount, R., Chorney, J., Zempsky, W., Rodrigues, N., \& Cousins, L. (2017): Management of pediatric pain and distress due to medical procedures. Handbook of pediatric psychology, 146.

- Elgazzar, S., \& Keshk, L. (2018): Effect of a construction educational protocol on nurses' knowledge, performance, and its effect on patient satisfaction undergoing cardiac catheterization. International Journal of Advanced Nursing Studies, 7(2), 100-106.

- Greenberg, J., Lunsford, L., \& Niranjan, A. (2019): Anesthesia Considerations during Leksell Radiosurgery. In Leksell Radiosurgery (Vol. 34, pp. 63-72). Karger Publishers.

- Hearps SJ, McCarthy MC, Muscara F, Hearps SJ, Burke K, Jones B, \& Anderson VA. (2014): Psychosocial risk in families of infants undergoing surgery for a serious congenital heart disease. Cardiol Young; 24:632-639.

- Heikkinen, H. (2020): The effects of a child's long-term illness on the work of early childhood educators.

- Hockenberry, M., Wilson, D., \& Rodgers, C. (2016): Wong's essentials of pediatric nursing: Elsevier Health Sciences.

- Kanter, J., Bergersen, L., Coombs, S., Forbes, T. Everett, A., \& Martin, G. (2015): Pediatric cardiac catheterization databases. In Pediatric and Congenital Cardiac Care (pp. 243-257). Springer, London.

- Kaugars, A., Shields, C., \& Brosig, C. (2018): Stress and quality of life among parents of children with congenital heart disease referred for psychological services. Congenital heart disease, 13(1), 72-78.

- Kobayashi, D., Turner, D., Forbes, T., \& Aggarwal, S. (2018): Parental anxiety among children undergoing cardiac catheterization. Cardiology in the Young, 28(2), 315-321.

- Lakatos, P., Matic, T., Carson, M., \& Williams, M. (2019): Child-parent psychotherapy with infants hospitalized in the neonatal intensive care unit. Journal of clinical psychology in medical settings, 26(4), 584-596.

- Lovibond, P., \& Lovibond, S. (1995): The structure of negative emotional states: Comparison of the Depression Anxiety Stress Scales (DASS) with the Beck Depression and Anxiety Inventories. Behavior research and therapy, 33(3), 335-343.

- Mirhosseini, H., Moosavipoor, S., Nazari, M., Dehghan, A., Mirhosseini, S., Bidaki, R., \& Yazdian-Anari，P. (2015): Cognitive-behavioral development in children following maternal postpartum depression: a review article. Electronic physician, 7(8), 1673.

- Nakamura, K., Sakhuja, R., \& Jang, I. (2021): Cardiac Catheterization and Intervention. In MGH Cardiology Board Review (pp. 191-222). Springer, Cham.

- Siu, A., Bibbins-Domingo, K., Grossman, D., Baumann, L., Davidson, K., Ebell, M., \& US Preventive Services Task Force. (2016): Screening for depression in adults: US Preventive Services Task Force recommendation statement. Jama, 315(4), 380-387.

- Tesson, S., Butow, P., Sholler, G., Sharpe, L., Kovacs, A., \& Kasparian, N. (2019): Psychological interventions for people affected by childhood-onset heart disease: A systematic review. Health Psychology, 38(2), 151.

- Thrush, P., \& Hoffman, T. (2014): Pediatric heart transplantation-indications and outcomes in the current era. Journal of thoracic disease, 6(8), 1080. 